\title{
Partial Pericardial Defect in an Asymptomatic Patient and Brief Review of Literature
}

\author{
Rauniyar RK, Sah PL, Gupta MK, Dhungel K, Ahmad K, Ansari S
}

Department of Radiodiagnosis and Imaging, BPKIHS, Dharan, Nepal

\begin{abstract}
Congenital absence of pericardium is rare. Pericardial defects can be complete or partial. Partial pericardial defect may be symptomatic. We report a rare case of partial pericardial defect in an asymptomatic patient which was suggested by chest radiograph and confirmed by computed tomography and brief review of literature is also presented.
\end{abstract}

Keywords: Asymptomatic patient, Partial pericardial defect

\section{Introduction}

Congenital absence of pericardium is a rare entity. ${ }^{1}$ Pericardial defects can be complete or partial. Most of them are left sided and asymptomatic. The diagnosis of absent pericardium is usually made at surgery or autopsy. ${ }^{1,2,3}$ We report a rare case of partial pericardial defect in asymptomatic patient which was suggested by chest radiograph and confirmed by computed tomography and review literature.

\section{Case description}

A 80 years old female patient reported in Radiology Department for routine chest Xray examination for some other reason. She did not have any chest complain. General and systemic examinations were

Correspondence to: Dr. R K Rauniyar, Professor and Head of Department, Department of Radiodiagnosis and Imaging, BPKIHS, Dharan, Nepal

Email Id: rauniyar99@yahoo.com unremarkable. Chest radiograph posteroanterior view (Fig. 1) revealed a focal bulge in the middle of the left heart border. One of the differential diagnosis as focal pericardial defect was suspected and Echocardiography was done which revealed defect of pericardium in left heart border. Rest of Echocardiographic findings was unremarkable. Non-contrast Computed Tomography (CT) of the thorax (Fig.2) revealed incomplete pericardial defect on left side. The patient is on regular follow up for last 1 year and is doing well without any complication.

\section{Discussion}

Congenital absence of pericardium is rare. Southworth $\mathrm{H}$ and Stevenson CS found only 1 case of pericardial defect in over 14000 autopsy performed at the John Hopkins Hospital. ${ }^{1}$ It occurs more commonly in men than women, however our reported patient is a female. Pericardial defects may be complete or partial. Most pericardial defects 
are partial and occur on the left side. Occasionally, defects may occur on the right side or at the diaphragmatic surface. ${ }^{4}$

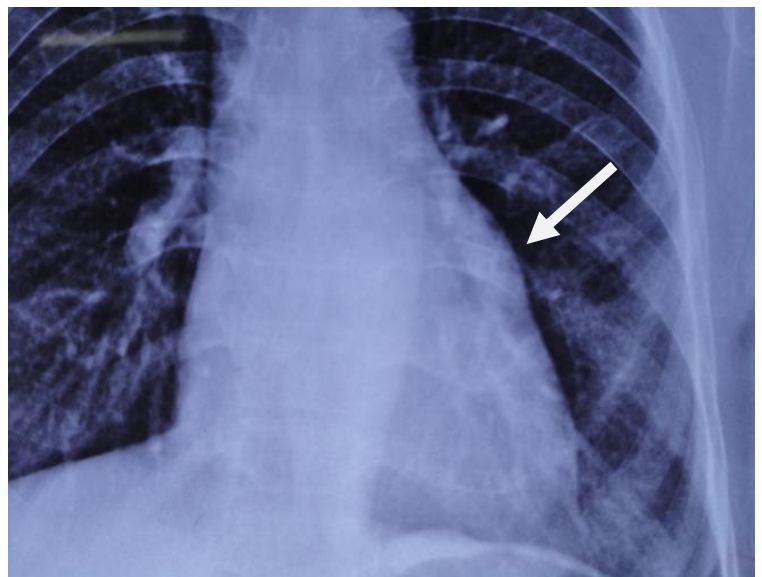

Fig 1: Chest X-ray PA view showing prominence of mid left heart border.

Defective closure of the pleuropericardial membranes lead to the congenital absence or partial defect of the pericardium. Different theories have been proposed to explain why the pericardial defect is common on left side. The most accepted theory is the one proposed by Perna and by Plaut. The left common cardinal vein tends to atrophy and is represented by coronary sinus in adult. The right common cardinal vein finally develops into the superior vena cava. Premature atrophy of left common cardinal vein results in deficient blood supply to pleuropericardial membrane, thereby, causing its incomplete development. ${ }^{5,6,7}$

Congenital pericardial defects are frequently asymptomatic and discovered only during autopsy or thoracotomy. ${ }^{8}$ The most common presenting symptom is chest pain. The exact mechanism of chest pain has not been well defined. Myocardial ischemia due to impingement of fibrous pericardial rim on coronary arteries is one of the cause of the chest pain. ${ }^{9}$ Dyspnoea, syncope are other symptoms that have been reported. ${ }^{10}$ Partial pericardial defect may also cause sudden death of the patient. ${ }^{11}$ Patients who have a pericardial defect with associated congenital abnormalities are often symptomatic and have one or more abnormalities, including atrial septal defect, patent ductus arteriosus, mitral valve stenosis, or tetralogy of Fallot. ${ }^{4}$ Pericardial defect may be associated with bronchogenic cyst or diaphragmatic hernia. $^{12,13,14}$

In the past, the diagnosis of pericardial defect was often established on chest radiography by iatrogenic induction of left pneumothorax which has become obsolete now days. Spontaneous pneumothorax, if present on left side, aid in its diagnosis. ${ }^{15}$

Chest radiograph often raises suspicion as in our case. The findings of pericardial defect on chest radiograph include rotation of the heart into the left chest with the right cardiac border projected over the midline, prominent contour of the left cardiac border with accentuation of the convexities of the aortic knob, the main pulmonary artery and the left ventricle. There may be an area of hypotransparency between the aortic arch and the pulmonary artery, which is the result of the interposition of the pulmonary tissue at this level. ${ }^{6,10}$

Differential diagnosis on plain film include atrial dilatation, mitral stenosis, and causes of enlargement of the pulmonary artery like idiopathic dilatation of the pulmonary artery, hypertension from any cause, pulmonary valvular stenosis, large left-to-right shunts (especially atrial septal defect) and rarely pulmonary arteriovenous aneurysm or ventricular aneurysm. Clinical features and echocardiography will be useful to exclude these conditions. ${ }^{16}$ 

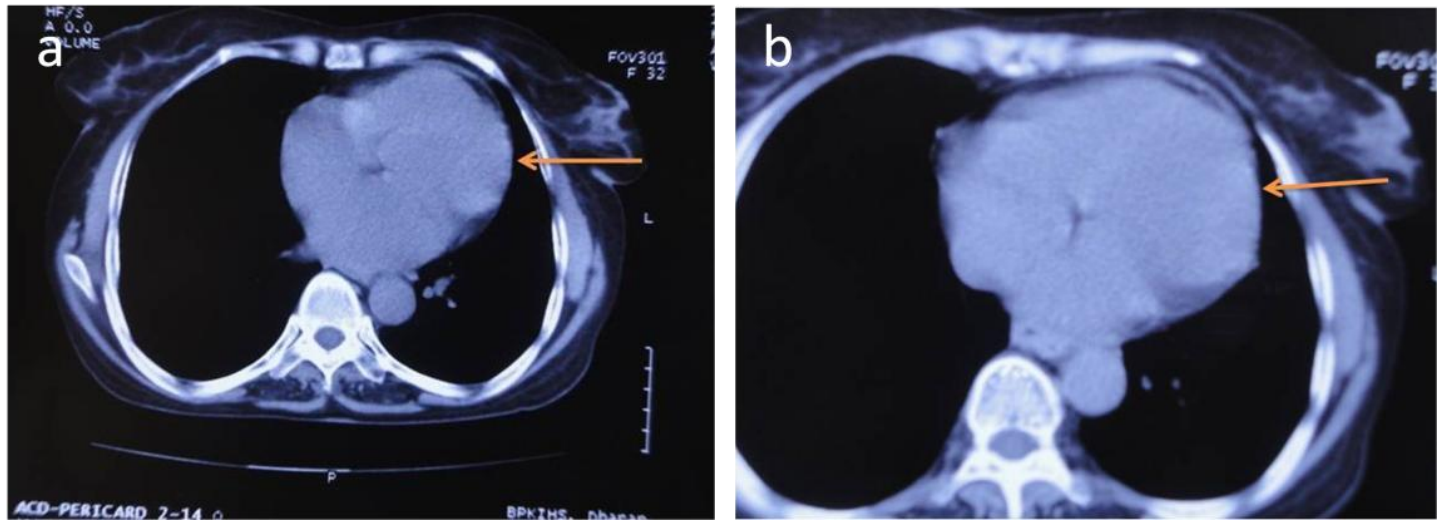

Fig 2: CT scan of the chest showing localized focal partial absence of pericardium on left side (a). Magnified view (b).

Although radiographs may show evidence of this condition, a definitive diagnosis can be obtained with CT or MR imaging. ${ }^{17,18,19}$

Excessive myocardial displacement and a large difference in total heart volume in the end-systolic and end-diastolic phases on functional MRI have been proposed for diagnosis of congenital absence of pericardium. $^{20}$

Complications of congenital pericardial defect may include herniation and entrapment of a cardiac chamber, especially the left atrial appendage. Therefore, prophylactic closure of partial pericardial defects has been recommended. ${ }^{21}$

Surgical closure or enlargement of the defect is sometimes necessary to alleviate herniation. Small defect require treatment whereas large and total absence of the left pericardium can be left untreated. ${ }^{7,13}$

\section{Conclusion}

Focal pericardial defect might impose diagnostic challenge on chest radiography. MDCT is useful modality to confirm its diagnosis. Early detection of partial pericardial defect is essential to avoid further complications.

\section{References}

1. Southworth H, Stevenson CS. Congenital defects of the pericardium. Arch Intern Med. 1938;61: 223-240.

2. Shimada Y, Yoshida J, Aokage K, Hishida $T$, Nishimura $M$, Nagai $K$. Complete left-sided pericardial defect in a lung cancer patient undergoing pneumonectomy without closure of the defect. Ann Thorac Cardiovasc Surg. 2011;17(1):67-70.

3. Drury NE, De Silva RJ, Hall RM, Large SR. Congenital defects of the pericardium. Ann Thorac Surg. 2007 Apr;83(4):1552-3.

4. Wang ZJ, Reddy GP, Gotway MB, Yeh BM, Hetts SW, Higgins CB. CT and MR imaging of pericardial disease. Radiographics. 2003 Oct;23 Spec No:S167-80. Review.

5. Perna G. Sopra un arresto di sviluppo della sierosa pericardica nell'uomo. Anat Anz 1909;35:323-338. 
6. Plaut, Martha: Ueber zwei weitere Falle von Defekt des Herzbeutels, Frankfurt Ztschr. f. Path. Wiesb. 1913;12:141-156.

7. Moore RL. Congenital deficiency of the pericardium. Arch Sug. 1925;11:765. 67

8. Faridah Y, Julsrud PR. Congenital absence of pericardium revisited. Int $\mathrm{J}$ Cardiovasc Imaging. 2002 Feb;18(1):6773. Review.

9. Nguyen DQ, Wilson RF, Bolman RM 3rd, Park SJ. Congenital pericardial defect and concomitant coronary artery disease. Ann Thorac Surg. 2001 Oct;72(4):1371-3.

10. Gatzoulis MA, Munk MD, Merchant N, Van Arsdell GS, McCrindle BW, Webb GD.Isolated congenital absence of the pericardium: clinical presentation, diagnosis, and management. Ann Thorac Surg. 2000 Apr; 69(4):1209-15.

11. Brunning EG. Congenital defect of the pericardium. J Clin Pathol. 1962 Mar;15:133-5.

12. Mukerjee S. Congenital partial left pericardial defect with a bronchogenic cyst. Thorax. 1964 Mar;19:176-9.

13. Imperatori A, Rotolo N, Nardecchia E, Mariscalco G, Spagnoletti M, Dominioni L. Bronchogenic cyst associated with pericardial defect: case report and review of the literature. J Cardiothorac Surg. 2011 Jun 20;6:85.

14. Verloes A, Perrin L, Delbecque K, Gonzales M, Demarche M, Dekoster G.Congenital absence of the left pericardium and diaphragmatic defect in sibs. Eur J Med Genet. 2010 MayJun;53(3):133-5.

15. Pickhardt PJ. Congenital absence of the pericardium confirmed by spontaneous pneumothorax. Clin Imaging. 1998 NovDec;22(6):404-7.

16. Pernot C, Hoeffel JC, Henry M, Frisch R, Brauer B. Partial left pericardial defect with herniation of the left atrial appendage. Thorax. 1972 Mar;27(2):24650.

17. Jacob JL, Souza Junior AS, Parro Junior A. Absence of the left pericardium diagnosed by computed tomography. Int J Cardiol. 1995 Jan 6; 47(3):293-6.

18. Rusk RA, Kenny A. Congenital pericardial defect presenting as chest pain.Heart. 1999 Mar;81(3):327-8.

19. Gassner I, Judmaier W, Fink C, Lener M, Waldenberger F, Scharfetter $\mathrm{H}$, Hammerer I. Diagnosis of congenital pericardial defects, including a pathognomic sign for dangerous apical ventricular herniation, on magnetic resonance imaging. $\mathrm{Br}$ Heart J. 1995 Jul;74(1):60-6.

20. Psychidis-Papakyritsis P, de Roos A, Kroft LJ. Functional MRI of congenital absence of the pericardium. AJR Am J Roentgenol. 2007 Dec;189(6):W312-4.

21. Robin E, Ganguly SN, Fowler MS. Strangulation of the left atrial appendage through a congenital partial pericardial defect. Chest. 1975 Mar;67(3):354-5. 